\title{
Violence at work: determinants \& prevalence among health care workers, northwest Ethiopia: an institutional based cross sectional study
}

\author{
Dawit Getachew Yenealem ${ }^{1 *}$, Manay Kifle Woldegebriel ${ }^{2}$, Ararso Tafese Olana ${ }^{3}$ and Tesfaye Hambisa Mekonnen ${ }^{1}$
}

\begin{abstract}
Background: Workplace violence is the intentional use of power, threatened or actual, against another person or against a group, in work-related circumstances, that either results in or has a high degree of likelihood of resulting in injury, death, psychological harm, mal development, or deprivation. The aim of this study is to assess magnitude and predictors of workplace violence among healthcare workers in health facilities of Gondar city.

Methods: Institutional based cross sectional study design was employed to conduct this study. The study conducted in Gondar town from February 21 to march 21, 2016. Five hundred fifty three health care workers selected from health facilities of Gondar City administration. A stratified sampling technique was used for selecting the study subjects through simple random sampling. Data was collected by structured self administered questionnaire which is adapted from ILO/ICN/WHO/PSI after it is pretested \& prepared in Amharic. The data was coded and entered in to EPI info version 7 and exported to SPSS version 20 software for analysis. The degree of association for variables was assessed using odds ratios with 95\% confidence interval and $p$-value $\leq 0.05$.

Results: The prevalence of workplace violence was found to be $58.2 \%$ with [95\% confidence interval (CI): $(53.7,62.3)]$ in which verbal abuse 282(53.1\%) followed by physical attack 117(22.0\%) and 38(7.2\%) sexual harassment. Working at emergency departments [AOR $=3.99,95 \% \mathrm{Cl}:(1.49,10.73)]$, working at shifts [AOR $=1.98,95 \%$, Cl: $(1.28,3.03)]$,short experiences $[\mathrm{AOR}=3.09,95 \% \mathrm{Cl}:(1.20,7.98)]$, being nurse or midwife $[\mathrm{AOR}=4.06,95 \% \mathrm{Cl}:(1.20,13.74)]$ were positively associated with workplace violence. The main sources of violence are visitors/patient relatives followed by colleagues and patients.

Conclusion: workplace violence is major public health problem across health facilities and the Ministry of Health should incorporate interventions in its different health sector development \& management safety initiative.
\end{abstract}

Keywords: Health facilities, Health care workers, Workplace violence, Gondar

\section{Background}

Workplace violence is the intentional use of power, threatened or actual, against another person or against a group, in work-related circumstances, that either results in or has a high degree of likelihood of resulting in injury, death, psychological harm, mal development, or deprivation [1]. It has become an alarming phenomenon

\footnotetext{
* Correspondence: dawaitgetachew105@gmail.com

${ }^{1}$ Department of Environmental and Occupational Health and Safety, Institute of Public Health, College of Medicine and Health Sciences, University of Gondar, P.O. Box 196, Gondar, Ethiopia

Full list of author information is available at the end of the article
}

worldwide and one of the largest public health problem [2]. Even though workplace violence occurred on both private \& public HCWs South African study shows public HCWs are more exposed than their private counterparts [3]. The rate of assaults on health workers is higher than that of other occupations-eight assaults per 10,000 workers compared with two per 10,000 for the general workplace [4].

Workplace violence causes ill health [5]. A longitudinal study on nurses demonstrates those who exposed to workplace violence develops higher somatic \& musculoskeletal disorder symptoms than the comparison groups [5]. A

(c) The Author(s). 2019 Open Access This article is distributed under the terms of the Creative Commons Attribution 4.0 International License (http://creativecommons.org/licenses/by/4.0/), which permits unrestricted use, distribution, and reproduction in any medium, provided you give appropriate credit to the original author(s) and the source, provide a link to the Creative Commons license, and indicate if changes were made. The Creative Commons Public Domain Dedication waiver (http://creativecommons.org/publicdomain/zero/1.0/) applies to the data made available in this article, unless otherwise stated. 
global review of 150,000 nurses shows that third of have been physically assaulted, bullied, or injured, while around two-thirds have experienced nonphysical assault [4]. A retrospective database review among United States nurses about cost of workplace violence find annual workplace violence charges for the $2.1 \%$ of nurses reporting injuries were $\$ 94,156$ ( $\$ 78,924$ for treatment and $\$ 15,232$ for indemnity) [6].

In Ethiopia Most of healthcare workers are women in which they are exposed for both domestic \& workplace violence which is a double burden [7]. Even though workplace violence studies mostly focuses on psychiatric and emergency department settings it is significantly prevalent in general healthcare workers [2].

Healthcare workers who exposed to workplace violence result to enormous consequences [8]. A systematic review of literature comes up with seven types of consequences namely: physical, psychological, emotional, work functioning, relationship with patients/quality of care, social/general, and financial. Psychological (e.g., posttraumatic stress, depression) and emotional (e.g., anger, fear) consequences and impact on work functioning (e.g., sick leave, job satisfaction) [9]. The most frequent and important effects of workplace violence as Longitudinal study from Finland shows physical violence lead to increment on intention of physician to leave while job satisfaction is affected by both bulling \& physical violence [10]. In musculoskeletal studies WPV especially physical violence shows a significant role in predisposing to acute \& chronic low back pain in study in Iran [11]. The consequences workplace violence extends beyond economic burden to be matter of quality of life [12].

In Ethiopia Very little information is available about workplace violence among healthcare workers. Considering large number of work force in health care sector in which majority of them are women. Currently government concern \& intervention is limited domestic violence. But violence is not limited to house hold level and tackling demands comprehensive knowledge \& focusing its effect on healthcare delivery as well. This study will provided a comprehensive baseline of workplace violence in healthcare workers which helps concerned bodies to initiates \& start to shape strategies.

\section{Methods}

\section{Study design, sample size determination, sampling technique}

Institutional based quantitative cross sectional study was conducted in Gondar city in march 2016. Gondar is one of tourist destination city in Ethiopia, which is $747 \mathrm{~km}$ from Addis Abeba and $170 \mathrm{~km}$ from regional capital Bahir Dar. According to CSA 2014 projection Gondar has 323,875 populations reside in it. There are one university hospital 8 health centres. In addition 1 medium hospital, 13 specialty clinics, 15 medium clinics \& 11 primary clinics according to Gondar city administration health department. About 994 health care workers employed at all level of health facilities. Sample size was determined by using single population proportion formula, taking $29.9 \%$ [13] prevalence of workplace violence from previous study in Hawassa.95\% confidence interval margin of error of $4 \%$. The final sample size was 553.

Stratified sampling techniques were used for selecting the study subjects. First of all healthcare workers were stratified in to private \& government then further classified according to their type or level. Proportional numbers of health care workers were selected from each strata of health facility by simple random sampling technique.

\section{Data collection tools and procedures}

Data were collected by structured self administered questionnaire which is adapted to fit with this research objective from [ILO/ICN/WHO/PSI] [14] after it is pretested \& prepared in Amharic. The questionnaire was divided in to four parts. The first part was socio-demographic \& occupational characteristics like gender, age, educational status, profession, type of facility, working hour, working section and marital status. The second, third \& fourth section contains physical violence, verbal abuse \& sexual harassment respectively with relevant related questions. Four environmental and occupational health professionals working in the city was used to collect the data from. Two environmental health professional from Gondar university student services were assigned to supervise the data collection process. Both data collectors and supervisors was given a one day training on aim of study procedures of collection \& exercise it. The questionnaire was discussed thoroughly question by question. The study participants were made to fill the questionnaire in their respective health facility.

\section{Data processing and analysis}

All the questionnaires were checked manually, coded and entered in to EPI info version 7.1.5.2 and exported to SPSS version 20 software for analysis of potentially explanatory variables. Descriptive analyses were performed to describe variables using summery measure, frequencies, figures \& tables. 12 month WPV was evaluated by running bivirate logistic regression. Then variables with the $P$-value $\leq 0.2$ analyzed in multivariable regression. The degree of association between dependant \& independent variables was assessed using odds ratios within $95 \%$ confidence interval $p$-value $\leq 0.05$. workplace violence is ascertained when the study respondents experienced at least one type of workplace violence (i.e. physical violence, verbal abuse or sexual harassment) in circumstances related to their work in the past 12 months. 


\section{Results}

\section{Socio demographic characteristics of respondents}

The response rate was $96.02 \%(N=531)$.Among respondents $361(68.0 \%)$ were from government \& private hospitals and the rest were from private clinics and health centres. In addition 255(48.0\%) were males and 276(52.0\%) were females. The median age was $27, \mathrm{IQR}=7$ years with the range of 20 to 56 . Majority $289(54.4 \%)$ of healthcare workers are between the age group of 26-35 years. Among total participants majorities $415(78.2 \%)$ are belong to government health facilities while the rest work at private facilities116 (21.8\%).In respect to educational status 405(76.3\%) of HCWs have degree \& above qualifications in their professions (Table 1).

Table 1 Socio demographic characteristics of health care workers working at health facility at Gondar city administration, March 2016 $(n=531)$

\begin{tabular}{|c|c|c|}
\hline Variables & Frequency & Percentage \\
\hline \multicolumn{3}{|l|}{ Sex } \\
\hline Male & 255 & 48.0 \\
\hline Female & 276 & 52.0 \\
\hline \multicolumn{3}{|l|}{ Age } \\
\hline$\leq 25$ & 76 & 14.3 \\
\hline $26-35$ & 289 & 54.4 \\
\hline$\geq 36$ & 166 & 31.3 \\
\hline \multicolumn{3}{|l|}{ Religion } \\
\hline Orthodox & 454 & 85.5 \\
\hline Muslim & 56 & 10.5 \\
\hline Others & 21 & 4.0 \\
\hline \multicolumn{3}{|l|}{ Educational status } \\
\hline Diploma & 126 & 23.7 \\
\hline Degree & 361 & 68.0 \\
\hline Masters & 31 & 5.8 \\
\hline Specialty & 13 & 2.4 \\
\hline \multicolumn{3}{|l|}{ Marital status } \\
\hline Married & 245 & 46.1 \\
\hline Divorced & 10 & 1.9 \\
\hline Single & 276 & 52 \\
\hline \multicolumn{3}{|l|}{ Profession } \\
\hline Nurse/midwife & 339 & 63.8 \\
\hline $\mathrm{HO}$ & 34 & 6.4 \\
\hline Pharmacy/laboratory & 111 & 20.9 \\
\hline Other HCWs & 24 & 4.5 \\
\hline GP & 23 & 4.3 \\
\hline \multicolumn{3}{|l|}{ Facility ownership } \\
\hline Private & 116 & 21.8 \\
\hline Government & 415 & 78.2 \\
\hline
\end{tabular}

NB: Others: Protestant/catholic/Adventist

\section{Prevalence of workplace violence}

More than half $(58.2 \%)$ [95\% CI: $(53.7,62.3)$ ] of health care workers experienced at least one of manifestation of workplace violence (physical, verbal \& sexual) in the past 12 months. Health care workers mostly encountered verbal abuse 282(53.1\%) followed by physical attack $117(22.0 \%)$ and $38(7.2 \%)$ sexual harassment. Among all one third $(33.0 \%)$ of health care workers were a victim of two forms of workplace violence of the study while only $4.2 \%$ of participant reported they were experience all forms. Over one third (37.9\%) had witnessed physical violence on colleagues on their working environment. Females are most exposed in all forms of workplace violence: verbal abuse 161(57.1\%), physical attack 69(59.0\%) \& sexual harassment $38(100 \%)$ than men.

\section{Workplace characteristics of healthcare workers}

Two third 363(68.4\%) of respondents reveal that unavailability of workplace violence reporting procedures in their health facility. Inpatient departments are places where one third $168(31.6 \%)$ of the health care workers spent their time in the health facility. More than half of all health care workers have short experiences of less than six years (Table 2).

\section{Associations between exposure to types of violence and organizational and workplace characteristics}

Higher risk of physical violence was related to working at shift, in inpatient department, govermet facilities and having lower years of experience. A total of $54.7 \%$ of health care workers with fewer than 5 years of experience reported physical violence, which decrease \& increase with increase in experience. Physical violence was mostly reported in government workers $(86.3 \%)$ compared with privately owned facilities. There is no any association is observed between all forms of violence in relation to job position \& availability of reporting procedure. Verbal abuse showed stronger relationship similar to physical violence with stronger risk in facility ownership. Sexual harassment demonstrated lower relationship with organizational \& workplace characteristics, which is limited with working department \& ownership of the facility (Table 3 ).

\section{Factors associated with workplace violence}

In univarate analysis profession, level of facility, experience, department, age, Employment status, health facility ownership, shifts work becomes significantly associated with workplace violence. In fitting these variables in to multivariate analysis only, department, profession, shift work and experience remain significant.

Occupational setting of health care workers demonstrated that the odds of violence against health care workers were nearly about four times higher among emergency department workers than those served in outpatient 
Table 2 Organizational and workplace characteristics of healthcare workers working at health facilities of Gondar city administration, March 2016, $(n=531)$

\begin{tabular}{|c|c|c|}
\hline Variables & Frequency & Percentage \\
\hline \multicolumn{3}{|l|}{ Facility type } \\
\hline Hospital & 361 & 68.0 \\
\hline Health center & 92 & 17.3 \\
\hline Private clinics & 78 & 14.7 \\
\hline \multicolumn{3}{|l|}{ Violence Reporting procedure } \\
\hline Available & 168 & 31.6 \\
\hline Unavailable & 363 & 68.4 \\
\hline \multicolumn{3}{|l|}{ Department } \\
\hline Inpatient departments & 188 & 35.4 \\
\hline Pharmacy/laboratory & 108 & 20.3 \\
\hline Emergency departments & 46 & 8.7 \\
\hline Other departments & 25 & 4.7 \\
\hline OPD & 164 & 30.9 \\
\hline \multicolumn{3}{|l|}{ Experiences(in years) } \\
\hline $1-5$ & 308 & 58.1 \\
\hline $6-10$ & 151 & 28.4 \\
\hline $11-15$ & 15 & 2.8 \\
\hline $16-38$ & 57 & 10.7 \\
\hline \multicolumn{3}{|l|}{ Job position } \\
\hline Staff/service provider & 484 & 91.2 \\
\hline Ward/clinic head & 40 & 7.5 \\
\hline Coordinator & 7 & 1.3 \\
\hline \multicolumn{3}{|l|}{ Shift work } \\
\hline Yes & 336 & 63.3 \\
\hline No & 195 & 36.7 \\
\hline
\end{tabular}

department $(\mathrm{AOR}=3.99,95 \% \mathrm{CI}$ : $(1.49,10.73))$. Working at shifts revealed that it exposed to violence two times compared to those who worked at day shifts $(\mathrm{AOR}=1.98$, 95\% CI: $(1.28,3.03))$. Health care providers of $1-5$ years of experiences are three times at risk of encountering violence at work in contrast to $16+$ year served colleagues $(\mathrm{AOR}=3.09,95 \% \mathrm{CI}:(1.20,7.98))$. Working as nurse \& midwife in the health care facilities is four times more likely to experience violence than the general practitioners $(\mathrm{AOR}=4.06,95 \% \mathrm{CI}:(1.20,13.74))$ (Table 4).

\section{Discussion}

To the best of our knowledge this research is the first comprehensive research of workplace violence on health care both in profession \& type of health facilities covered in Ethiopia. Being nurse/midwife by profession, working in emergency department, shift work and having short experiences are significantly associated with workplace violence.
The study finds out $58.2 \%$ of respondents encounter WPV. This is higher than what is reported by WHO. The overall 12 month prevalence of workplace violence among healthcare workers is in line with study findings in South Africa (61.9) [3], Thailand (54.1) [15] and Turkey(57.5\%) [16]. This may be due to the methodological similarities employed in the studies. And it is lower than study in Nigeria (69.4) [17] and Oromiya, Ethiopia (88.0) [18] as it may be the fact that both studies doesn't include private sectors which relatively have low prevalence than government counterparts. Even the Ethiopian study is only on hospitals \& nurses in which known for their higher prevalence of workplace violence.

Workings in emergency departments have positive association with workplace violence. Those who work in clinical setting of emergency are four times exposed to workplace violence than OPD workers. An emergency working setting is where peoples are come in panic, with serious injuries that make them to be aggressive at health care providers. This is a place where life threatening health conditions and death make visitors \& patient relatives to be violent. All these fuelled by nervousness of HCWs which attributed to high workload \& stress. This finding is similar with study conducted in Hawassa, Ethiopia [13]. Similar emergency service delivery system, violence handling \& security condition may account for the similarity of results. In addition despite of target population difference those who work in emergency departments mostly are nurses. A more higher risk reported from Italian [19] study on both physical violence \& threats. This disagreement happens since healthcare workers from developed nation will report incidents more frankly \& correctly as their system responds proactively for employees safety.

Shift work appears to be an exacerbating factor for the encountering of workplace violence among health care workers. Those working at shifts are more likely to experience workplace violence than their colleagues of day shift. This finding is supported study from China [2]. Working in shift implies low level of security in the institution, fewer staff in the department and decreased work performance between staffs initiate conditions favourable for violence. Even limited or no presence of hospital administration also can be attributed. While a study from Turkey [20] shows lower association than our research. This might be due that higher workplace violence prevention interventions are provided in such developed country than this study setting.

Year of experience in health facilities have positive association with the occurrence of workplace violence. Those who have less than 6 years of experience 3 fold more likely victimized by violence than their seniors with more than 16 years of experience in the health care facilities. This may be health care workers with short 
Table 3 Organizational and workplace characteristics of healthcare workers working at health facilities of Gondar city administration with type of violence, March 2016, $(n=531)$

\begin{tabular}{|c|c|c|c|c|c|c|}
\hline \multirow[t]{3}{*}{ Variable } & \multicolumn{2}{|c|}{ Physical violence } & \multicolumn{2}{|l|}{ Verbal abuse } & \multicolumn{2}{|c|}{ Sexual harassment } \\
\hline & yes & no & yes & no & yes & no \\
\hline & $n(\%)$ & $n(\%)$ & $n(\%)$ & $n(\%)$ & $n(\%)$ & $n(\%)$ \\
\hline \multicolumn{7}{|l|}{ Job position } \\
\hline Staff/service provider & 107(22.1) & $377(77.9)$ & $231(47.7)$ & $253(52.3)$ & $37(7.6)$ & 447(92.4) \\
\hline Ward/clinic head & $9(22.5)$ & $31(77.5)$ & $24(60.0)$ & $16(40.0)$ & $1(2.5)$ & $39(97.5)$ \\
\hline Coordinator & $1(14.3)$ & $6(85.7)$ & $5(71.4)$ & $2(28.6)$ & $0(0.0 \%$ & $7(100.0)$ \\
\hline \multicolumn{7}{|l|}{ Shift work } \\
\hline Yes & $96(28.6)^{* *}$ & $240(71.4)$ & $209(62.2)^{* *}$ & $127(37.8)$ & $29(8.6)$ & $307(91.4)$ \\
\hline No & $21(10.8)$ & 174(89.2) & $73(37.4)$ & $122(62.6)$ & $9(4.6)$ & $186(95.4)$ \\
\hline \multicolumn{7}{|l|}{ Experiences(in years) } \\
\hline $1-5$ & $225(54.3)^{*}$ & 83(70.9) & $184(65.2)^{*}$ & $124(49.8)$ & $37(97.4)$ & $271(55.0)$ \\
\hline $6-10$ & 130(31.4) & 21(17.9) & $67(23.8)$ & 84(33.7) & $0(0.0)$ & 151(30.6) \\
\hline $11-15$ & $14(3.4)$ & $1(0.9)$ & $6(2.1)$ & $9(3.6)$ & $0(0.0)$ & $15(3.0)$ \\
\hline $16-38$ & $45(10.9)$ & $12(10.3)$ & $25(8.9)$ & $32(12.9)$ & $1(2.6)$ & $56(11.4)$ \\
\hline \multicolumn{7}{|l|}{ Department } \\
\hline Inpatient departments & $64(54.7)^{* *}$ & 124(30.0) & $119(42.2)^{* *}$ & $69(27.7)$ & $20(52.6)^{*}$ & 168(34.1) \\
\hline Pharmacy/laboratory & $6(5.1)$ & 102(24.6) & 53(18.8) & $55(22.1)$ & $3(7.9)$ & 105(21.3) \\
\hline Emergency departments & $22(18.8)$ & $24(5.8)$ & $34(12.1)$ & $12(4.8)$ & $6(15.8)$ & $40(8.1)$ \\
\hline Other departments & $3(2.6)$ & $22(5.3)$ & $7(2.5)$ & $18(7.2)$ & $2(5.3)$ & $23(4.7)$ \\
\hline OPD & $22(18.8)$ & 142(34.3) & $69(24.5)$ & $95(38.2)$ & $7(18.4)$ & 157(31.8) \\
\hline \multicolumn{7}{|l|}{ Ownership } \\
\hline Private & $16(13.7)^{*}$ & $100(24.2)$ & $44(15.6)^{* *}$ & $72(28.9)$ & $3(7.9) *$ & 113(22.9) \\
\hline Government & $101(86.3)$ & $314(75.8)$ & 238(84.4) & 177(71.1) & $35(92.1)$ & 180(77.1) \\
\hline \multicolumn{7}{|l|}{ Violence Reporting procedure } \\
\hline Available & $37(31.6)$ & 131(31.6) & $44(15.6)$ & $72(28.9)$ & $10(26.3)$ & 158(32.0) \\
\hline Unavailable & $80(68.4)$ & 283(68.4) & 238(84.4) & 137(71.1) & $28(73.7)$ & $335(68.0)$ \\
\hline
\end{tabular}

experience and mostly young are lacking the skills of managing violent conditions which can be acquired through experiences. The result is less than a study in Hawassa [13]. The difference may be due the difference in study subjects by profession. As Hawassa study is only on the nurses, who are deemed the most vulnerable while our study comprises all health professionals. The Congolese [21] study come up with a nearly no association results. The inconsistency can be by difference in sample size as the Congolese one is a nationwide study \& it doesn't includes violence arising from co-workers which leads to a normality across all experience categories.

Practicing a specific profession is a significant factor that exhibits visible association with workplace violence. Being a nurse or midwife had increased encountering workplace 4 times than working as physician. This is supported by research from Saudi [22]. This can be reason out since nurses are the front liners in giving service in health facilities in which patients \& patient's relatives spent more of their health facility times with them. Lower risk is reported from Brazil [23] \& Serbia [24]. This observable difference may be the difference of healthcare system in which professionals exposed to patients \& other potential sources of violence. In addition the proportion of nurses or midwifes \& physicians involved in these studies are not as large as this study involves which decrease the risk of exposure.

In this study Respondents rated long waiting time for the service and lack of security condition as the primary causes that facilitate occurrence of workplace violence. This claim of HCWs supported by researches from the Middle East countries [22, 25].when patient/ client wait for long time to get service they become irritated \& dissatisfied which results to quarrelling with HCWs and even assaulting verbally \& physically. Addressing long waiting time is also matter of improving the quality of service that ministry of health strives. 
Table 4 Univariate \& multivariate logistic regression of factors associated with workplace violence among health care workers working at health facilities in Gondar, March 2016 $(n=531)$

\begin{tabular}{|c|c|c|c|c|}
\hline \multirow[t]{2}{*}{ Variables } & \multicolumn{2}{|c|}{ Workplace violence } & \multirow[t]{2}{*}{$\operatorname{COR}(95 \% \mathrm{Cl})$} & \multirow[t]{2}{*}{$\mathrm{AOR}(95 \% \mathrm{Cl})$} \\
\hline & Yes & no & & \\
\hline \multicolumn{5}{|l|}{ Working department } \\
\hline Emergency & 40 & 6 & $7.71(3.10,19.20)^{* * *}$ & $3.99(1.49,10.73)^{* *}$ \\
\hline Inpatient & 131 & 57 & $2.66(1.71,4.11)$ & $1.41(0.78,2.55)$ \\
\hline Other $^{a}$ & 8 & 17 & $0.54(0.22,1.33)$ & $0.42(0.16,1.11)$ \\
\hline Pharmacy/laboratory & 54 & 54 & $1.15(0.71,1.88)$ & $0.91(0.24,3.47)$ \\
\hline OPD & 76 & 88 & 1 & 1 \\
\hline \multicolumn{5}{|l|}{ Shift work } \\
\hline Yes & 227 & 109 & $2.87(1.99,4.13)^{* * *}$ & $1.98(1.28,3.03)^{* *}$ \\
\hline No & 82 & 113 & 1 & 1 \\
\hline \multicolumn{5}{|l|}{ Years of experiences } \\
\hline $1-5$ & 206 & 102 & $2.40(1.35,4.26)^{* *}$ & $3.09(1.20,7.98)^{*}$ \\
\hline $6-10$ & 71 & 80 & $1.05(0.57,1.95)$ & $1.38(0.55,3.51)$ \\
\hline $11-15$ & 6 & 9 & $0.79(0.25,2.52)$ & $1.47(0.36,6.01)$ \\
\hline $16+$ & 26 & 31 & 1 & 1 \\
\hline \multicolumn{5}{|l|}{ Occupation } \\
\hline Nurse/ Midwife & 221 & 118 & $6.74(2.44,18.62)^{* * *}$ & $4.06(1.20,13.74)^{*}$ \\
\hline $\mathrm{HO}$ & 13 & 21 & $2.23(0.66,7.46)$ & $2.49(0.61,10.06)$ \\
\hline Pharmacist/Laboratory & 56 & 55 & $3.66(1.27,10.56)$ & $3.63(0.60,21.88)$ \\
\hline Other ${ }^{\mathrm{b}}$ & 14 & 10 & $5.04(1.40,18.14)$ & $4.06(0.91,18.11)$ \\
\hline GP & 5 & 18 & 1 & 1 \\
\hline \multicolumn{5}{|l|}{ Ownership } \\
\hline Private & 49 & 67 & 1 & 1 \\
\hline Government & 260 & 155 & $2.29(1.50,3.49)^{* * *}$ & $1.22(0.56,2.66)$ \\
\hline \multicolumn{5}{|l|}{ Type of facility } \\
\hline Hospitals & 231 & 130 & $3.35(2.00,5.61)^{* * *}$ & $1.20(0.48,3.03)$ \\
\hline Health center & 51 & 41 & $2.35(1.26,4.37)$ & $1.23(0.44,3.43)$ \\
\hline Private clinics & 27 & 51 & 1 & 1 \\
\hline \multicolumn{5}{|l|}{ Age(in years) } \\
\hline$\leq 25$ & 36 & 40 & $0.55(0.32,0.95)^{*}$ & $1.69(0.69,4.14)$ \\
\hline $26-35$ & 170 & 119 & $0.87(0.59,1.29)$ & $1.38(0.86,2.25)$ \\
\hline$\geq 36$ & 103 & 63 & 1 & 1 \\
\hline \multicolumn{5}{|l|}{ Employment } \\
\hline Full timer & 296 & 201 & 1 & 1 \\
\hline Contract & 13 & 21 & $0.42(0.20,0.85)^{*}$ & $1.10(0.42,2.87)$ \\
\hline
\end{tabular}

NB: statically significant at ${ }^{*}=p<0.05,{ }^{* *}=p \leq 0.006,{ }^{* *}=p \leq 0.0001$

aliaison, central supply, physiotherapy, anaesthesia, $x$-ray, card room, triage

${ }^{b}$ physiotherapist, anthesist, optometrists, psychiatrists, radiographers

The study clearly shows that policy \& working strategies should steer towards reducing factors aggravating workplace violence: such as log waiting time. In addition result related to absence of violence reporting procedure significantly related to having effective prevention of workplace violence.
The study will come with possible limitations like Recall bias which emanates as respondents expected to remember the past 12 month exposure. Having wider study subject coverage by profession \& Inclusion of both government and private facilities will be considered as strength since it will give a picture of all health care workers. 


\section{Conclusions}

Workplace violence appears to be major occupational hazard \& public health problem despite it is neglected both by victims and health facilities. Short experiences, working in emergency department, shift work \& being nurse/midwife has positive association with workplace violence.

\section{Abbreviations}

ART: Anti retroviral therapy; EPI-info: Epidemiological Information; GP: General Practitioner; HCW: Health Care Worker; ICN: International Council of Nurses; ICU: Intensive care unit; ILO: International Labor Organization; IQR: Inter quartile range; MCH: Maternal and child health; OPD: Outpatient department; PSI: Public Service International; SPSS: Statistical Package for the Social Sciences; TB: Tuberculosis; WHO: World Health Organization; WPV: Workplace Violence

\section{Acknowledgements}

We are grateful to the University of Gondar for the technical and financial support. We would also like to thank the Gondar city health administration \& all health facilities for their collaboration and guidance while conducting this study. We would also thank the participants of the study for their time to involvement in the study.

\section{Funding}

University of Gondar provides fund for the research without any role in the design of the study and collection, analysis, and interpretation of data and in writing the manuscript.

\section{Availability of data and materials}

All the necessary data is included in the manuscript document

\section{Authors' contributions}

DGY participated in the design of the study, data collection, analyzed the data and drafted the paper and the correspondence author. MKW, ATO approved the proposal with some revisions, participated in data analysis and drafted and revised subsequent drafts of the paper. THM Involved in writing up of the research proposal, data analyses, and wrote up the draft of the manuscript. All authors read and approved the final manuscript.

\section{Ethics approval and consent to participate}

Ethical clearance was obtained from institutional review board (IRB) of University of Gondar. Formal letter of cooperation was presented to respective governmental \& private health facilities. Each respondent were informed about the objective of the study, how the result will contribute for employers \& government in shaping policies concerning workplace violence. Respondent were involved after they give informed consent. Confidentiality of the data was maintained and respected. They also informed that all data collected kept confidentially just for only the purpose of study.

\section{Consent for publication}

Not applicable.

\section{Competing interests}

The authors declare that they have no competing interests.

\section{Publisher's Note}

Springer Nature remains neutral with regard to jurisdictional claims in published maps and institutional affiliations.

\section{Author details}

${ }^{1}$ Department of Environmental and Occupational Health and Safety, Institute of Public Health, College of Medicine and Health Sciences, University of Gondar, P.O. Box 196, Gondar, Ethiopia. ²Department of Public Health, College of Health Science and Comprehensive Specialized Hospital, Aksum University, Axum, Ethiopia. ${ }^{3}$ Department of Public Health, College of Medicine and Health Science, Ambo University, Ambo, Ethiopia.
Received: 19 October 2018 Accepted: 17 February 2019

Published online: 03 April 2019

\section{References}

1. Cooper, C. and N. Swanson, Workplace violence in the health sector-State of the Art. Geneva: ILO www.who.int/entity/violence_injury_prevention/injury/en/ WVstateart.pdf Accessed 20 may 2017.

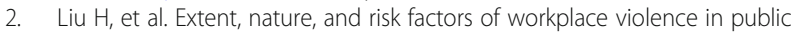
tertiary hospitals in China: a cross-sectional survey. Int J Environ Res Public Health. 2015;12(6):6801-17

3. Steinman, S., Workplace violence in the health sector country case study: South Africa. http://www.who.int/violence_injury_prevention/violencel interpersonal/en/WVcountrystudysouthafrica.pdf Accessed 10 may 2017.

4. Nelson R. Tackling violence against health-care workers. Lancet. 2014; 383(9926):1373-4

5. Yang L-Q, et al. Psychosocial precursors and physical consequences of workplace violence towards nurses: a longitudinal examination with naturally occurring groups in hospital settings. Int J Nurs Stud. 2012;49(9):1091-102.

6. Speroni KG, et al. Incidence and cost of nurse workplace violence perpetrated by hospital patients or patient visitors. J Emerg Nurs. 2014;40(3):218-28.

7. Semahegn A, Mengistie B. Domestic violence against women and associated factors in Ethiopia; systematic review. Reprod Health. 2015:12:1-12.

8. Newman CJ, et al. Workplace violence and gender discrimination in Rwanda's health workforce: increasing safety and gender equality. Hum Resour Health. 2011;9:1-13

9. Lanctôt N, Guay S. The aftermath of workplace violence among healthcare workers: a systematic literature review of the consequences. Aggress Violent Behav. 2014;19(5):492-501.

10. Heponiemi T, et al. The prospective effects of workplace violence on physicians' job satisfaction and turnover intentions: the buffering effect of job control. BMC Health Serv Res. 2014;14(1):1-8.

11. Karahan A, et al. Low back pain: prevalence and associated risk factors among hospital staff. J Adv Nurs. 2009:65(3):516-24.

12. Lin $W Q$, et al. Workplace violence and job performance among community healthcare Workers in China: the mediator role of quality of life. Int J Environ Res Public Health. 2015;12(11):14872-86.

13. Fute $\mathrm{M}$, et al. High prevalence of workplace violence among nurses working at public health facilities in southern Ethiopia. BMC Nurs. 2015;14:1-5.

14. ILO/PSI/WHO/ICN, workplace violence in the health sector country case studies reasearch instruments,survey questionnaire. www.who.int/violence_injury_ prevention/violence/...en/WVquestionnaire.pdf Accessed 20 may 2017. 2002.

15. Sripichyakan, K., P. Thungpunkum, and B. Supavititpatana, Workplace violence in the health sector. 2001

16. Aytac S, Dursun S, Akalp G. Workplace violence and effects on turnover intention and job commitment: a pilot study among healthcare workers in Turkey. Eur Sci J, ESJ. 2016:12(10):458-65.

17. Abodunrin $\mathrm{O}$, et al. Prevalence and forms of violence against health care professionals in a South-Western city, Nigeria. Sky J Med Med Sci. 2014;2(8):67-72

18. Jira C. Assessment of the prevalence and predictors of workplace violence against nurses working in referral hospitals of Oromia regional state, Ethiopia. JIMS8M: J Indian Manag Strateg. 2015;20(1):61-4.

19. Magnavita N, Heponiemi T. Violence towards health care workers in a public health Care Facility in Italy: a repeated cross-sectional study. BMC Health Serv Res. 2012;12(1):1.

20. Pinar $\mathrm{T}$, et al. Workplace violence in the health sector in Turkey: a National Study. J Interpers Violence. 2015:1-21.

21. Muzembo BA, et al. Workplace violence towards Congolese health care workers: a survey of 436 healthcare facilities in Katanga province, Democratic Republic of Congo. J Occup Health. 2015;57(1):69-80.

22. Algwaiz WM, Alghanim SA. Violence exposure among health care professionals in Saudi public hospitals. A preliminary investigation. Saud Med J. 2012;33(1):76-82

23. Palácios, M., et al., Workplace violence in the health sector. Country case studyBrazil. ILO, ICN, WHO and PSI joint Programme on workplace violence, 2003.

24. Fisekovic MB, et al. Does workplace violence exist in primary health care? Evidence from Serbia. Eur J Pub Health. 2015;25(4):693-8.

25. El-Gilany AH, El-Wehady A, Amr M. Violence against primary health care workers in Al-Hassa, Saudi Arabia. J Interpers Violence. 2010;25(4):716-34. 